\title{
Relationship School-Family-Community: When All Learn with All
}

\author{
Maria Martins ${ }^{1}$, Teresa Sarmento ${ }^{2}$ \\ (1. Agrupamento de Escolas Viseu Sul, Portugal; 2. Instituto de Educação - Universidade do Minho, Portugal)
}

\begin{abstract}
Despite the weak involvement of families in the school life of their children, there is a widespread perception and a tacit acceptance of the importance of this involvement and implication, by the strong and positive correlation that it has with the school and educational success of children, adolescents and youngsters.

In a research carried out under the $\mathrm{PhD}$ in Educational Sciences and from the perception of parents and teachers who play the roles of Class Tutors, it was possible to identity very significant benefits that can result from a close and constructive relationship between the school, the surrounding community, and particularly families.

The joint reflection on these results as well as the objective to put it at the service of the improvement of the school educational activity, the project "Parents and Teachers in Training/Action" was born. Aiming the promotion of an active and informed participation of families in their children's school careers and relying on the commitment of the internal actors, this project chooses as primary intervention strategy the training of parents and teachers as they are more directly responsible in the educational process. Through the development and deepening — by specialized teams — topics, mostly suggested by recipients, a contribution to the construction of a space of reflection around the complex daily school life is provided, in joint pursuit of the most appropriate responses to the problems and constraints that characterize it.
\end{abstract}

Key words: partnerships, parental involvement, project

\section{Introduction}

The little collaboration of the parents/Guardians and the strong negative correlation with the academic performance and behavior of the students is recognized a difficulty that the school has to face, constituting our scholar context a case where this problem has a great relevance.

As the possible explanatory causes of this withdrawal from the parents towards the scholar life of their children are concerned, we are aware that the difficulties that may be due to their lack of time, because of their working life, of some lack of interest, of sensibility or of ability to participate in it, of cultural discontinuity with the school, of devaluation of its role..., there are the constraints created by the scholar institution itself. These difficulties are the result of its organizational structure, bureaucratic routines, lack of appropriate spaces to attend the parents, inadequacy of the schedules of the directors of the class to do that attendance, lack of specialized training to the exercise of that function — factors that concur to the withdrawal of the families.

Thus, to the reality of many parents of difficult access, using the language of Davis (1989, p. 24), we cannot

Maria Martins, Ph.D., Teacher, Agrupamento de Escolas Viseu Sul, Portugal; research areas: parental involvement. E-mail: mariamartinssousa@gmail.com

Teresa Sarment, Ph.D., Professor, Instituto de Educação-Institute of Education, Universidade do Minho-University of Minho; research areas: parental involvement, teaching teachers, identities. E-mail: TSarmento@ie.uminho.pt. 
subtract, the not less significant reality pointed out by Marques R. (2001, p. 24), of the schools difficult to reach.

To all of this we have to add the lack of a positive intervention, coordinated and intentional, on the part of the living forces of the community, namely through the institutions and other organizations, to better integrate and identify the school with that community and of help in the construction of a close, regular and constructive relation between the school and the families, especially those belonging to socioeconomic layers more underprivileged and culturally more distant from the school and that, for that reason, have more difficulties in involving and in becoming implicated themselves in the scholar life of their children.

The difficulties found in the establishment and development of an adequate typology of relationship and involvement of the parents in their children's school life are a factor that proves the need to trace coherent goals, based in the results of the most recent research and in the adequate knowledge of the specificities of the educational community, which envision a reflection and adoption of innovative strategies that will lead parents to come closer to school.

Zenhas (2006, p. 15), however, alerts to the fact that, being the collaboration between school-family-community, it is fundamental to lessen the difficulties derived from the cultural discontinuity between the school and a significant number of families, to overcome the difficulties and school dropout on the part of the students. If that collaboration is not preceded by a socioeconomic and cultural characterization of the scholar population and if it does not contemplate a diversified offer of activities that seek an adequacy to the different layers of that population, it may result in a contribution that is efficient only to the upper classes and represent a cultural continuity with the school, emphasizing even more the social cleavage existent between the lower classes and the school.

Thus, to proceed to the elaboration and implementation of strategies that lead to approach families from school and to a greater involvement of the guardians to the scholar dynamics of their children, it is really necessary to get acquainted with the reality of the school and of the families of the students who attend it. Only the perception, knowledge and recognizing of the specificities of the reality of the school, i.e., in possession of the elements that characterize them, will it be possible, consciously, delineate, to plan and implement the most adequate strategies and, consequently, having more chances to develop a culture of participation and involvement of all actor of the educational scene — school, family and surrounding community.

Essentially because of the responsibilities inherent to our professional activity, namely the exercise of the functions of the direction of a class, that we have been performing for over two decades, it was our intention to develop, in the scope of our doctoral thesis ${ }^{1}$, a research project that, in accordance with the actual principles, the educational policies and the demands of society, — all of them oriented towards the need of a more significant participation of the families and of the community in the life of schools - as well as to a greater openness of the school to its surrounding environment, might contribute to the study of this reality that raises new and ever bigger problems to the pedagogical practice of teachers, to children, to families and to all those who are actors in the educational process.

Based on the perceptions of the parents/guardians and teachers who are holding functions of directors of the class, a characterization of the participation of families in the schools of a county of the Middle area of Portugal was conducted, namely as regards the kind and frequency of the contacts with the school, the constraints that have

\footnotetext{
1 Doctorat in Educational Sciences: "Relação Escola-Família: Análise Da Participação Das Famílias Nas Escolas EB 2,3 Do Concelho De Viseu( (Relationship between School-Famly: to analyze the participation from families to schools in a school of Viseu), realized in the University of Granada, 2012.
} 
been affecting their involvement, the benefits of that involvement, the areas in which their participation is more urgent and the strategies to be developed either by the school, either by the family and community, to reach a more significant and better approximation, implication and collaboration of the guardians in the scholar life of their children.

Among the results of this study, it was possible to identify a very positive perception on the part of the interviewees relatively to the potentialities and benefits of a close relation between the school and the families, being those results the focus of this article.

\section{Benefits of the Collaboration School-Family-Community: Around the Literature}

The educational action is a task of the whole of society, of all educational instances attended by the child. However, nobody denies the evidence that it is up to the family the first and permanent responsibility of guiding and developing skills that allow the construction of a project of living in accordance with her/his potentialities and aspirations. The Declaration of the Human Rights, itself, consecrates this idea, in the point 3 of its article 26th, that the parents have the priority of the right to choose the kind of education they want for their children.

It is, thus, within the family context that the set of cultural references that will serve as reading list of the social relationships and interactions, from the development of the skills that will allow the exercise of citizenry.

Thus, one understands that the school will not be capable to truly develop its role if it does not have the support of the community, namely of the family. It is the family that best knows the potentialities and specific characteristics of each student, being the actor in the better position to provide schools and teachers with that fundamental information to the development of more adequate projects and strategies. Parents, not only continue to be, despite all, the first and most important teachers of their children (Marujo, Neto \& Perloiro, 2005, p. 149), but they are also rightly, the biggest and the more valid resource that teachers have to help students (...) (Marujo, Neto \& Perloiro, 2005, p. 11).

From a close and positive relation between the school and the families result benefits to all intervenient in the educational action.

\subsection{Improvement of the Performance of the Students}

Marques R. (2001, p. 19) recalls that the studies realized in the last decades reveal, unequivocally, that when parents involve themselves, children have a better academic success. This author adds that the programs of involvement of the parents promote their collaboration in their children's study, at home, and reduce the taxes of dropout.

Sarmento T. and Marques J. (2009, p. 77) highlight that children are the first and more benefited with an appropriate involvement of their parents in schools. In fact, the greater coordination of strategies and convergence of interests and objectives that results from that approximation between the two educational instances promotes a greater affective and emotional balance, a feeling of a greater security and, consequently, an increased motivation and commitment in children.

Silva (2009, p. 116) stresses the consistency of the investigation when he considers that the closest the relation between schools and families, the higher the educational success of children and youngsters and that the literature mentions abundantly the benefits of this relation, besides referring to the academic success of the students.

In the same line of thought, Sousa (1998, pp. 148-150) recalls that the literature presents recurrently the 
involvement of the parents in school as being associated with multiple advantages. The child — student at the school, son or daughter at home and citizen in the community - feels more motivated and has a more positive attitude towards schools and to her/his learning, which fosters her/his success, the children being those who can benefit the most with that involvement. In short, we can state that a partnership work between the school and the families leads the student, because she/he feels more valued, to increase her/his interest by the school and, as a consequence, to improve her/his attitudes and behavior, as well as her/his academic success.

\subsection{Social Valorization and Improvement of Self-Esteem in Parents}

With their approximation to the school, parents feel socially valued, which constitutes a factor of considerable importance in the lower classes, leading to a reinforcement of the role of the association of parents and of their social legitimation.

Sousa (1998, pp. 148-150) adds that parents, because they feel that they are supported, have an improvement of their motivation and self-esteem, since the social networks that provide access to more information and support among their members are enlarged. Besides, as Davies (1989, p. 39) refers, a participation of parents, carefully prepared, based on democratic principles, and shall promote a more equalitarian distribution of the power of intervention among the several classes and groups of parents, highlighting the surplus value that it represents to the families with lower social and cultural capital.

Several authors also draw attention to the benefits that may result from the direct contact between parents, in their generalized participation in school. This relationship, this deeper acquaintance and sharing of experiences, promotes and strengthens the development and enlargement of the social networks, that may serve the purpose of promoting strategies of helping each other, which often reveal themselves to be more efficient than the help that can be offered by the teachers or by other institutions. The programs of involvement of parents in school, at the same time that they provide a greater confidence in schools, foster an increase of the parents' self-esteem, of their value and of their motivation to the exercise of their role as educators and a greater predisposition to help their children.

\subsection{Increase of Professional Satisfaction of Teachers}

The literature mentions and enunciates, also, the benefits that a good relationship between the school and the families may provide to teachers.

Silva (2009, pp. 116-119) refers that, from the involvement of families, teachers' satisfaction gets reinforced, since the objective of their efforts is the promotion of the effective academic success of the students, which is a result from such involvement.

In the same line of thought, Sousa (1998, pp. 148-150) considers that teachers, faced with parents' positive attitudes, provide them more and better quality information about the students and that support them in their educational task, that they have their work facilitated and their satisfaction increased. Likewise, Davies (1989, p. 40), citing Epstein (1986), highlights that teachers' work might be very simplified if they share with parents some of their concerns, work and responsibilities, since in these circumstances parents tend to have a more positive perception of the teacher.

With a greater approximation of the schools to the families, better conditions to develop a partnership work are created, for parents and teachers to get to know each other better, to be able to define and organize strategies and goals, contributing, thus, to a better academic performance of the students Consequently, the assessment conducted by parents regarding the actions of the teachers can be improved, as well as teachers' expectations 
regarding parents and children.

This approximation decidedly contributes to overthrow some barriers that still exist between the parents and guardians and the teachers.

\subsection{Benefits to the Local Community}

Davies (1989, p. 40) presents the community as one of the potential elements to benefit with the involvement of the families in the school life of their children. When it feels that it is being involved, through parents' participation, the community shall tend to reduce its distrust towards school, increasing its feeling of belonging to the school and intensifying the means of collaboration and identification with its problems and potentialities, which shall progressively lead teachers not to feel themselves the owners of the school, of knowledge and of education.

Sousa (1998, pp. 148-150) considers that, as regards the community, the gains in terms of development of the values of equality and democracy might be significant, besides the improvement of que quality of the options and coordination of the its services.

2.5 School: Improvement of the Educational Activity and of the Access to the Available Resources in the Community

The scholar institution, when it decentralizes itself and becomes closer to the other actors, improves the patterns of the educational quality.

In that line of thought, Miguéns (2005, p. 11) highlights, still, that the school, when involves all families, not only leads parents to actively participate in the education of their children, but also becomes a learning environment to parents, which, in turn, provides them more informed choices about educational projects to their children.

Marzano (2004, p. 50) adds that it can have its stock of resources substantially increased, not only in terms of knowledge and specific skills in certain areas, through the maximization of the cultural, social and scientific capital of some families, but also through the increase of contacts with the resources available in the community. In that line of thought, Sarmento T. \& Marques J. (2009, pp. 76-77) recall that an increased involvement of parents and guardians in the work of the school results in a progressive improvement on their perceptions about the activities of teachers and of the school and in a better understanding of those activities. This shift in posture of parents benefits the school, since it promotes, also according to the same authors, a greater visibility of the real needs of each school, in terms of equipment and materials (...), making it possible an increased allocation of resources to the school and the maximization of their profitability (ibid.).

\subsection{The School as Potential Laboratory of Democracy and Space of Citizenship}

The narrowing of the relation between school, family and community, implying an attitude of communication and participation of the different actors, induce, according to Silva (2003, pp. 116-119), one culture of citizenship and a deepening of democracy, both at the representative level, and at the participative one.

Summoning the reflection of Sarmento T. \& Marques J. (2009, p. 76), we should like to highlight the political changes that occurred after the Revolution of 1974, that have allowed significant changes, both in families and in school. These changes have been progressively maximizing and demanding a greater commitment and involvement of the families in school life, in the way of a team work that, in an active and co-responsible exercise of citizenship, promotes the scholar and academic success of children, teenagers and young people. 
Sarmento T. (2009, pp. 51-54), in an enlightening approach to that which she defends to be the right of the child to be listened to and to directly intervene in her/his process of socialization and training, a right that means to the child that society recognizes her/his social role, considers that school, understood as a space of life an agency of development of the communities, represents a privileged context for the exercise of the rights and duties of citizenship. She also recalls that is within this framework that the reflection on the relation between school-family-infancy-community ought to be conducted. That way, these connections, as windows to the construction of a society that guarantees space and gives voice to all of its citizens, consubstantiate the development and the existence of "communities of citizenship" capable of harboring, respecting and valuing its multicultural reality, as well as a "school of citizens", that promotes the construction of citizenship of all those who live in it or have some forma of relation with it.

We should like to point out that the education for citizenship is a transversal concern to all countries of the European Union. In a press briefing of the Eurydice Network, regarding the results of a study realized with the support of the European Commission on education to citizenship in Basic and Secondary Education, in 2005, entitled "The education for citizenship in the schools of Europe", the reinforcement of social cohesion and the active participation of citizens in social life are mentioned as core concerns, highlighting the role that school might play in that area, with the Council of Europe declaring 2005 as the European year of citizenship through education. In that document, it is recalled that the concept of "responsible citizenship is part, in a more or less explicit way, of the official/legal documents of the educational policy of all European countries, being associated with values such as democracy, defense of human rights, tolerance, solidarity and participation. In the same report, is mentioned that, although achieved in different ways in the different countries, in terms of curriculum, the education for citizenship is in general considered as a pillar of education.

And, because one learns how to collaborate, by collaborating, another advantage of this involvement of the parents in the scholar life of their children, participating in the development of projects and assuming an active and responsible role in the decision making processes of the institution, is, according to Silva (20 g to 03: 355), the fact that all that practice consubstantiates an increase of the democratization of the school and of its surrounding community, highlighting the mobilizing role that the school might perform in the communities, as an agents of their development.

We conclude, thus, that the achievement of a relation of partnership between the schools, the families and the communities, consubstantiate a reality that has obvious benefits to all intervenient.

\section{Knowing the Reality to Better Intervene: Results of the Empirical Study}

The commitment with the innovation and with the improvement of our educational practices, founded on critical and reflexive thinking around the reality in which we are submerged, constitutes the propelling of development force of this work of research, of which we present and highlight its results in terms of the benefits of a culture of participation of the families in the school life of their children.

Being, nowadays, ordinarily accepted that the existence and the quality of the relation school-family has a positive influence on the students' commitment and academic performance, maximized by the improvement of the self-esteem of parents and teachers, and aware that the degree and the quality of the involvement of the families directly depends on the representations that the latter have about the school, it is our conviction that the characterization of the reality and posterior joint reflection about the achieved results, may contribute to the 
promotion of the relation of proximity, to allow families to feel more that the school is also "their school".

Thus, based on the data collected during the doctoral research already mentioned, we begin by presenting the results of the representations of the group of the population constituted by the guardians regarding the advantages of a relation of collaboration school-family.

Through observation the results, it is possible to verify that, in the opinion of the guardians, the first and more important benefits that result from a relation of proximity between the school and the families are related to both students' scores and behavior (mentioned by $73 \%$ and by $67 \%$ of the interviewees, respectively). At some distance, but with a very significant level of incidence, are pointed out the increase of guardians' level of satisfaction (43\%), the fact that it helps the school to open itself up to the families and to the community (39\%), the increase in teachers' level of professional satisfaction (33\%), the contribution to a good image of the school (30\%) and the increase of the participatory democracy in the school (22\%).

We ought to highlight that in the option "others" are still mentioned benefits that have to do with the help it provides to get acquainted with the real problems and the understanding of the difficulties that the school faces to solve them in a time span that is satisfactory to parents and students, contributions that this relation may offer to a better society in general.

The fact that all options have been significantly chosen shoes that guardians have, clearly, the perception of the enormous advantages of a good relation between the school and the families, to all intervenient. Is shows, above all, their perception of the benefits that may result to their children's academic and behavioral performance, which is the ultimate goal for developing of that relation. One can conclude, thus, that, as also confirmed in the interviews, the guardians recognize the existence of benefits to all people involved, which stresses the generalized importance that is attributed to the parental participation in the school.

The same line of thought is adopted by the teachers of hold the functions of Director of the Class.

The analysis to the results about this question allows us to verify the alignment of the perception of the directors of the class with the one of the guardians. Considering that most of the former that the advantages of a good relation between the school and the family have to do essentially with the positive effects on students' behavior (88.9\%) and with their academic success (79.0\%), they point out, significantly, as benefits of the relation school-family the contribution that it can give to the school in its opening up to community (44.4\%), as well as the increase of guardians' level of satisfaction (42.0\%) and of teachers' (35.8\%), the contribution to foster democracy in school (32.1\%) and the social construction of a good image of the school (27.2\%).

One can conclude, thus, that also according to the opinion of the directors of the class, the first and main actors that are benefited are the students. When they feel more motivated, they have a more positive posture towards school and their learning activities, which maximizes their academic performance, and, consequently, their scholar and academic success. This idea is visible, as well, in the analysis of the interviews carried out with this group of interviewees, with one of the directors of the class highlighting the idea that that interaction is reflected in a very positive fashion in the learning and in the development of the knowing how to be and of how to live of his students $\left(\mathrm{DC}_{2}\right)$.

Notwithstanding, it is equally evident the recognition, on the part of directors of the class, of the advantages to all other educational actors. As a matter of fact, this relation contributes to make easier the lives and actions of all the people involved in the educational process; that is why this relation is considered fundamental to the three parts $\left(\mathrm{G}_{1}\right)$ : school, family and community. 
This convergence between guardians and directors of the class seems to us to be symptomatic and revealer of the importance of the need to promote and implement this relation of collaboration between the school and the families.

In this study, we also carried out an analysis of the crossing of the perceptions of the guardians with several social and demographic factors. We should like to highlight, at this moment, the results of the strong relation existent with their level of school.

Our research shows us that the importance attributed to all benefits of a good relation between the school and the family increases with the increase of level of school.

At this point, we can conclude that the level of school of the guardians is related, in a positive way, to the sensibility and degree of awareness regarding the scholar dynamics and to the proximity with the school, and, consequently, regarding its dominant culture. In the wake of Silva P. (2009b, p. 122), the sociological cleavage that crosses the relation school-family is pretty much situated here, with disadvantage to those who, because they are in cultural discontinuity with the school, have greater difficulties in the development of their participation and involvement in the scholar life of their children, leading the same author (2002, p. 114) to consider that, towards school, some parents are more equal than others.

Faced with this chart, we consider that it is fundamental to promote the development of adequate strategies, that help families to develop co-educational skills, to allow them to better accompany and supervise their children and that are capable of approaching and involve them.

Thus, it seems to us that it is evident that the school must assume a preponderant role in the development of those strategies to involve of all families. Besides the approximation, the school must provide to the families with lower academic level of school and, consequently, culturally more distant, the development of skills that allow them to truly accompany the scholar path of their children. We are talking about strategies that may include sensitizing and training actions through the so many times called "school of parents" and through more direct and individualized support that, due to their integrator function, may contribute to the disaggregation of the social cleavage in the relation school-family, as defended by Avelino (2005, p. 76). This author, considering that the communication must be a constant, presents a set of little strategies that the school may use to attract parents to the school and that include periodic thematic meetings with parents of each class or year; individual interviews in the beginning of the school year, whenever is deemed necessary; parties, social intercourse, drama, visits of study, the implementation of days of... and the regular use of written communication. Relatively to the so-called "school of parents", Santos (2009, pp. 149-154) presents his experience, as a psychologist, in one of those situations, starting to highlight that the goal to reach is not simply that parents come to the school, or return to the school, but also to be able to work with the families, based on the presupposition that education is a task of the quotidian, through the relationships that are established with children, a notion that is easier to apprehend if it is jointly shared with other parents. The idea is, thus, in a systemic and constructivist perspective, of stimulating the development of the parents' educational skills, increasing their self-confidence as educators, through the reflection and dialogue and help among parents, with the collaboration and supervision of specialized technicians, such as teachers, psychologists, social workers, etc. the author suggests that the most requested themes to be discussed are management of authority, sexuality, family relationships and the relation school-family, highlighting the benefits that this strategy may bring regarding parents' involvement in the scholarization of their children. Almeida (2009, p. 163), in defense of the institution of this strategy, recalls that the "school of parents" is a great instrument of intervention that may serve to, in depressed zones make more informal for parents to come to the school, being 
capable to help to provide them with knowledge and skills in the areas in which they have more difficulties dealing with their children.

In own perspective, the training of parents must start with the recognition and valuing of the skills that parents possess as educators, maximizing their opportunities and resources. Parents, though not always consciously, have an educational project for their children, evidenced in their expectations and strategies that they develop in daily life, even though these are opposite to what is understood as being the correct ones. As the people who, during a longer period of time, and with a greater power, influence their children, their way of being and of acting have to be taken into account in the training processes of the students, which lead us to understand training not as compensatory, but as redefining of support ways to the successful process of each child's personal development.

On the other hand, we underline the need for the school to rethink itself, in terms of organization and functioning, not only developing a greater sensibility towards the real difficulties felt by the families in de performance of their co-educative functions, but also, and above all, to develop a policy of real openness to the society, predisposing itself to the intervention and questioning of external agents and promoting a rupture with its traditional closeness and self-centeredness.

In the light of what has been stated, it becomes clear that the programs to improve the performance of the students through parental involvement may take several forms, with the schools developing and implementing the strategies deemed more adequate to their respective reality.

The theme that we have chosen was and continues to be, namely in Portugal, the subject of many studies, which has made our task easier, in terms of theoretical references. However, we reiterate our conviction about the relevance and usefulness of our study, since it is a very complex theme, and not always the studies address realities as specifics as it has been done in our work. Effectively, even though the results cannot be applied to the generality of all similar schools in the country, as we have circumscribed our study to just one school, the surplus value of this work comes, precisely, from the circumstance of our being able to produced knowledge about one specific reality, exceptionally, being the reality in which we professionally are emerged and about which we feel co-responsible.

As mentioned above, the purposes that guided the development of this study are founded in a philosophy and way of being, corresponding, in this case, to the desire of giving a contribution to a rupture in the organizational and functional grammar of the school, that makes it a more open and, even more importantly, attentive institution, more adequate to the real contingencies of the population fabric that it serves and, in the wake of Silva (2003), that knows how to integrate, valuing and taking advantage of the multiculturality that inhabits within its boundaries.

The importance and validity of this study extends to the practical implications of its results, namely regarding the sensitizing and sharing strategies promoted and to be promoted within the scholar and educational community, strategies that we hope shall contribute to improve the situation as regards the collaboration school-family-community, thus promoting students' academic success, through the improvement of the educational quality of this school.

Therefore, from the initial commitment to, in conformity with the results of this study, develop help programs to involve families, namely programs of parental training or other kind of actions to attract parents to school and school life/education of their children, was born and is being implemented a project of intervention. This project has as its main goal the creation of a space of joint reflection between those who are more directly 
responsible for the scholar and educational path of the children - parents/guardians and teachers, to which research purposes have to be added, now in a methodology of research-action, as well as the production and deepening of theoretical-practical knowledge in the scope of parental involvement.

\section{The Project "Parents and Teachers in Training/Action": An Intervention Founded on the Produced Knowledge}

Effectively, from the joint reflection around the results of the mentioned study, and in order to use it to improve the educational action of the school, it was born the project "Parents and Teacher in Training/Action".

\subsection{Mission/Goals}

This project has the fundamental mission of promoting a close and positive relation between the school and its surrounding environment, increasing the active and enlightened participation of families in school and in the scholar path of their children and promoting a work of greater proximity between guardians and teachers, to allow a better and more effective accompaniment of children. Thus, the general goals of this project are:

- To promote the participation of guardians in the scholar life of their children;

- To contribute to a greater openness of the school to the community;

- To promote the communication and interaction school-family-community.

\subsection{Responsible Team by the Project}

Our initial conviction led us to think that it was fundamental to constitute an enlarged and multidisciplinary team, to guarantee a capability to find responses as all-embracing as possible, to the expected requests that in reality were made.

Therefore, the team is composed by a total of 15 elements, among which there are six teachers of the district school, one element of the Direction, the psychologist responsible for the Guiding and Psychology Services, the President of the Association of Parents, three guardians, one social worker, one physician and two teachers of Superior Education, with the last four of them being appointed by their respective institutions, with which an collaboration agreement was established

\subsection{Strategy of Action}

Relying on the committed work of the internal actors to achieve this purpose, this project chooses as more intervention strategy the training of parents/guardians and of teachers, in their quality of more direct responsible in the educational process. Through the development and deepening — by specialized teams — of themes/issues - in its majority suggested by the trainees, a contribution to the construction of a space of regular answer around the complex scholar quotidian, to jointly search for the more adequate responses to the problems and constraints that characterize it.

It is our conviction that, through the clarification and one professional and relational language, and educational skills, as well as the agreement of wills and actions, this project may help to reduce differences and divergences between parents/guardians, and between these and teachers, in a posture of acceptance and valuing of different perspectives and their reconfiguration. This way, it will contribute to the development of a co-learning community and, consequently, truly co-educational, capable of sharing not only the responsibilities, but also the construction of solutions, anticipating a future that we all desire and needs more equity in terms of educational opportunities and, very concretely, as regards the effective participation of families in the life and scholar path of their descendent. 


\subsection{Implementation/Development}

After being approved by the Pedagogical Council, and after receiving the green light from the Direction of the District School, the project was presented first hand to the council of the directors of the class, because of the strategic relevance of their elements in the articulation with the guardians. Thus, the latter are the intermediates of the project, namely as regards the delivery and collecting of the inscription files to the implemented sessions. It was, also, asked that, in the moment of the election of the representatives of the parents, the project was made available, sensitizing the parents to choose a representative with the profile and availability to actively collaborate in the project.

In a second moment, a meeting was held with all representatives of the parents. With the presence of all elements, the team present the project, namely as the goals and methodology of action were concerned. To the representatives of the parents, it was asked an active participation in terms of mediation of information to the parents they represented, but also, and above all, a committed role regarding the sensitizing, the motivation and the mobilization of all parents to the actions to be implemented. Some decisions were taken about the periodicity of the sessions to be held and, besides the issues presented by the team, the representatives of the parents were invited to present others, request that was met with great enthusiasm. A decision was, also, taken about the theme of the first session, being agreed that, in each session, the decision about the theme of the following session would be made.

Therefore, starting with the typology of the defined action — the training — monthly sessions are held, each subordinated to an issue, chosen in a joint answering. To develop each issue, the project team invites specialized professionals in the subject. With some antecedence, all the community is informed about the issue and date of the following session, through the web page of the district school. The parents/guardians are invited to participate through an informative and inscription file. The delivery by the student and its respective collection is made by the director of the class.

Thirteen sessions have already been realized: "Guiding in the study", stimulated by the Guiding and Psychology Services of the district school; "Habits of a healthy diet ....”, by a team of health professionals of the Hospital of Viseu; "Education for sexuality; a multidisciplinary approach”, by a team of physicians of the Family Health Unit Grão Vasco; "Home work: quality and usefulness criteria”, by a retired teacher with a large experience in the scope of the educational inspection; "Study guiding for children with learning disabilities", by the Guiding and Psychology Services; "Children and youngster in the internet: tensions between potentialities and dangers”, by a group of teacher of the Escola Superior de Educação of Viseu; “Accidents with children: better to prevent", by a team of the Group Alert for Security; "II Seducation in Debate: School-Family-Community, stimulated by a researcher and teacher of the University of Minho and by a research journalist on the field of education; "I count with you”, by two teachers of Escola Superior de Educação de Viseu; “At home, at school, ... the no also educates", by a psychologist who was a guardian and directed to guardians of students of Pre-school and first cycle of Basic Education, an action replicated by the psychologists of the school district and directed to guardians of 2nd and 3rd cycles of Basic Education; "School and families in a context of crisis; reflecting and building solutions", by the psychologists of the school district and by a researcher of the University of Minho; “Drugs; what to do?”, by the Coordinator of the Prevention Team of the Center of Integrated Responses of Viseu.

The adhesion has been very positive, with the number of elements present in the sessions varying from 60 to 170. 


\subsection{Partnerships}

Implementing a project such as this implies, in the first place, the union of all scholar community in a collective effort to achieve the proposed goals. Nevertheless, it becomes necessary to seek and establish partnerships that provide the access to human resources, qualified and diversified, to find the more adequate responses to the requests. It is within the framework of the construction of surplus value that the several partnerships were established by Agrupamento de Escolas Viseu Sul with the Escola Superior de Educação de Viseu, with the University of Minho, with the Universidade Católica Portuguesa - Regional Center of Beiras and with the Association of Health Centers Dão Lafões.

In a brief synthesis about the communication here presented, we highlight the importance of the sustained knowledge about the issue of parental involvement, so the actions taken are implemented with clear goals and the previous assurance that they will be achieved. Thus, the creation of a project of intervention of a school, which, in this case, is designated by Parents and Teachers in Training/Action, consolidated fashion, evidenced the advantages of the relation school-families to educational success, showing, as well, the obstacles that the development of practices in this area face. Distinctly, parental involvement brings benefits to students, parents and teachers, even though their distribution depends on multiple factors, such as socio-cultural conditions of the families, the openness of teachers to keep a relationship with the parents and the organization of the school to the promotion of practices of collaboration. In counterpoint, the obstacles are found in negative representations, either of parents, or of teachers, regarding that relation, to which one can add time management problems and other organizational conditions. Committed with the benefits identified and with the support of previously developed practices, the project now designated by PPFA seeks, through a convergence of interests and motivations of parents and teachers, to make effective target school. Along with this, the development of the project with a research foundation promotes the deepening of the development of reflection skills and, in some cases, even of research, which constitutes itself as a new way of knowledge building, where the professionals of the action identify themselves, simultaneously, as authors of theoretical production.

\section{References}

Almeida A. (2009). “Good practices school/family/comunnity”, in: National Council of Education (org.), School, Family and Comunnity, Lisboa: CNE, pp. 161-164.

Avelino O. (2005). "Participation of parents in school life and in the monitoring of children - The importance of tuning and consistency”, in: National Council of Education (Org.), Education and Family, Lisboa: CNE, pp. 73-78.

Davies D. (Dir.) et al. (1989). Schools and Families in Portugal - Reality and Perspectives, Lisboa: Livros horizonte, Lda. DRE (2013). “Universal declaration of human rights”, available online at: http://dre.pt/comum/html/legis/dudh.html.

Marques R. (2001). Educating with Parents, Lisboa: Editorial Presença.

Miguéns M. I. (2005). “Previous new”, in: National Council of Education, Education and Family, Lisboa: CNE, pp. 9-12.

Marujo H. A., Neto L. M. and Perloiro M. F. (2005). The Family and School Success (4th ed.), Lisboa: Edições Científica Editorial Presença.

Marzano R. J. (2004). How to Manage Schools to Educational Success, Virginia: Edições ASA.

Santos L. (2009). “Good practices school/family/comunnity”, in: National Council of Education (org.), School, Family and Comunnity, Lisboa: CNE, pp. 149-154.

Sarmento T. (2009). “Children and citizenship: participatory approaches in educational projects”, in: Sarmento T., Ferreira F. I., Silva P. \& Madeira R., Childhood, Family and Community - Children as Social Actors, Porto: Porto Editora, Lda, pp. 43-68.

Sarmento T. and Marques J. (2009). School and Parents, Maia: Livraria Minho, U.M.

Silva Pedro (2003). School-Family, One Rigged Relationship: Intercultural Relations and Power, Porto: Edições Afrontamento.

Silva Pedro (2009). “O contributo da escola para a atividade parental, numa perspetiva de cidadania”, in: National Council of Education, School, Family, Community, Lisboa: CNE, pp. 115-140. 
Sousa L. (1998). Children (Con)fused between School and Family - A Systematic Perspective for Students with Special Educational Needs, Porto: Porto Editora, LDA.

Zenhas A. (2006). The Role of the Form Tutor in Collaboration School - Family, Porto: Porto Editora. 